\title{
FEDERALISMO E POLICY ARENAS: UMA ANÁLISE A PARTIR DA ATUAÇÃO DOS CONSÓRCIOS NO BRASIL ${ }^{1}$
}

Lizandro Lui

Letícia Maria Schabbach ${ }^{3}$

Este artigo investiga o estabelecimento de convênios entre os consórcios públicos intermunicipais e a União à luz dos debates sobre cooperação interfederativa e policy arenas. Para isso, analisou-se o conteúdo dos convênios celebrados entre os consórcios e a União nas áreas de meio ambiente, resíduos sólidos, saneamento básico, desenvolvimento rural e agricultura, disponíveis no Portal da Transparência da União, no período de 1996 a 2016. Procurou-se identificar as principais áreas de atuação dos consórcios, o tipo de atividades que realizam, e dar ênfase para as estruturas de regulação existentes em cada área de políticas públicas. Identificou-se que os consórcios se apresentam como importantes instâncias de articulação entre os entes federados e que essas organizações buscam se inserir nas policy arenas de distintas políticas públicas. Por fim, argumenta-se que a atuação dos consórcios tem como objetivo atenuar os efeitos negativos que o federalismo brasileiro provoca nos municípios.

Palavras-chave: cooperação interfederativa; consórcios públicos; policy arenas.

\section{FEDERALISM AND POLICY ARENAS: AN ANALYSIS FROM THE PERFORMANCE OF CONSORTIAS IN BRAZIL}

The article investigates the establishment of agreements between inter-municipal public consortia and the Union in the light of debates on inter-federative cooperation and policy arenas. To this end, the content of the agreements signed between consortia and the Union in the area of environment, solid waste, basic sanitation, rural development and agriculture were analyzed, available at the Transparency Portal of the Union, from 1996 to 2016. Searched identify the main areas of activity of consortia, the type of activities they carry out and emphasize the existing regulatory structures in each area of public policies. It was identified that the consortia are presented as important instances of articulation between the federated entities and that these organizations seek to insert themselves in the policy arenas of different public policies. Finally, it is argued that the work of consortia aims to mitigate the negative effects that Brazilian federalism causes in municipalities.

Keywords: inter-federative cooperation; public consortia; policy arenas.

\section{FEDERALISMO Y POLICY ARENAS: UN ANÁLISIS DEL DESEMPEÑO DE LOS CONSORCIOS EN BRASIL}

El artículo investiga el establecimiento de acuerdos entre consorcios públicos intermunicipales y la Unión a la luz de los debates sobre cooperación interfederativa y ámbitos políticos. Con este fin, se analizó el contenido de los acuerdos firmados entre los consorcios y la Unión en

1. DOI: http://dx.doi.org/10.38116/ppp55art6

2. Pesquisador na Diretoria de Estudos e Políticas Regionais, Urbanas e Ambientais (Dirur) do Ipea. E-mail: <lizandrolui@ gmail.com>.

3. Professora do Programa de Pós-Graduação em Sociologia do Instituto de Filosofia e Ciências Humanas da Universidade Federal do Rio Grande do Sul (IFCH/UFRGS).E-mail:<leticiams65@gmail.com>. 
materia de medio ambiente, residuos sólidos, saneamiento básico, desarrollo rural y agricultura, disponibles en el Portal de Transparencia de la Unión, de 1996 a 2016. Búsqueda identificar las principales áreas de actividad de los consorcios, el tipo de actividades que realizan y enfatizar las estructuras reguladoras existentes en cada área de políticas públicas. Se identificó que los consorcios se presentan como instancias importantes de articulación entre las entidades federadas y que estas organizaciones buscan insertarse en los ámbitos políticos de las diferentes políticas públicas. Finalmente, se argumenta que el papel de los consorcios tiene como objetivo mitigar los efectos negativos que el federalismo brasileño causa en los municipios.

Palabras clave: cooperación interfederativa; consorcios públicos; policy arenas.

\section{FÉDÉRALISME ET POLICY ARENAS: UNE ANALYSE DE LA PERFORMANCE DES CONSORTIUMS AU BRÉSIL}

L'article examine la mise en place d'accords entre les consortiums publics intercommunaux et l'Union à la lumière des débats sur la coopération inter-fédérative et les arènes politiques. À cette fin, le contenu des accords signés entre les consortiums et l'Union dans les domaines de l'environnement, des déchets solides, de l'assainissement de base, du développement rural et de l'agriculture a été analysé, disponible sur le portail de transparence de I'Union, de 1996 à 2016. Identifier les principaux domaines d'activité des consortiums, le type d'activités qu'ils mènent et mettre l'accent sur les structures réglementaires existantes dans chaque domaine des politiques publiques. II a été identifié que les consortiums sont présentés comme d'importants exemples d'articulation entre les entités fédérées et que ces organisations cherchent à s'insérer dans les arènes politiques des différentes politiques publiques. Enfin, il est avancé que le rôle des consortiums vise à atténuer les effets négatifs que le fédéralisme brésilien provoque dans les municipalités.

Mots-clés: coopération inter-fédérative; consortiums publics; arènes politiques.

JEL: H53; R50.

\section{INTRODUÇÃO}

O estudo tem como objetivo analisar a atuação dos consórcios públicos intermunicipais a partir dos dados oferecidos pelo Portal da Transparência, no período 1996-2016. Para este artigo, os convênios celebrados entre a União e os consórcios foram selecionados por área temática, quais sejam: meio ambiente, resíduos sólidos e saneamento básico e agricultura. A escolha dessas áreas se deve ao fato de que já existe um conjunto de estudos relacionados à atuação dos consórcios intermunicipais de saúde no Brasil (Lima, 2000; Nicoletto, Cordoni Júnior e Costa, 2005; Amaral e Blatt, 2011; Botti et al., 2013; Morais e Chaves, 2016; Silva et al., 2017; Lui, 2019; Lui e Schabbach, 2020) e uma carência de estudos que enfatizam as outras áreas de atuação dos consórcios. Nesse sentido, o artigo tem como objetivo contribuir com a literatura, analisando o funcionamento dos consórcios públicos em múltiplas áreas de atuação. Nesta pesquisa, estamos tratando de consórcios públicos, visto que estes possuem personalidade jurídica própria para contrair direitos e obrigaçóes, como, por exemplo, celebrar convênios com a União e prestar contas depois. 
A temática da cooperação federativa na implementação de políticas públicas tem permeado o debate contemporâneo sobre o federalismo. Além da clássica tríade "União, estados e municípios", novos arranjos institucionais, como comitês, conselhos, comissóes e consórcios, também passaram a ser importantes para a análise. Conforme apontam Segatto e Abrúcio (2016), uma das questôes mais importantes no debate sobre o federalismo se refere à compatibilidade entre a diversidade, característica do federalismo, e a garantia de políticas sociais universais. Segundo os autores, a análise das políticas sociais em sistemas federativos mostra que a coordenação do governo federal tem capacidade de reduzir a heterogeneidade na implementação feita pelos governos subnacionais.

Em relação aos estudos sobre coordenação federativa, os autores apontam que elementos como a distribuição de recursos, o estabelecimento de padróes e a regulamentaçáo nacional garantem uma homogeneidade entre as mais diferentes regiōes em áreas de políticas públicas (Arretche, 2004; Abrucio, 2005; Lotta, Gonçalves e Bitelman, 2014; Segatto e Abrucio, 2016; Couto e Bellon, 2018). Além disso, eles apontam que os estudos sobre coordenação federativa deram, historicamente, mais atenção ao papel do governo federal enquanto indutor das relaçóes intergovernamentais, deixando de lado o papel dos outros entes federados. A contribuiçẫo deste estudo para a literatura será apresentar novos dados a respeito da coordenação federativa no Brasil, observando a forma como os consórcios públicos intermunicipais se inserem no contexto.

Os consórcios existem há muitos anos no Brasil, e inúmeras pesquisas foram realizadas enfocando o funcionamento desses arranjos institucionais. Conforme Strelec e Fonseca (2011) e Machado e Andrade (2014), os consórcios públicos surgem como uma forma de inovação institucional para a gestão municipal e como instrumentos de planejamento regional para uma possível solução de problemas comuns. Os autores concordam com o fato de que, para os municípios, os consórcios assumem um importante papel, tendo em vista que eles permitem o acesso a um conjunto de produtos e serviços que alguns governos municipais não teriam condiçóes de adquirir. Ademais, apontam para o fato de que um conjunto de políticas públicas demanda uma atuação regional, tais como meio ambiente, gestão de resíduos sólidos, saúde, entre outras, e que os consórcios poderiam ser instrumentos interessantes para a articulação política entre os municípios.

É possível identificar, analisando a literatura sobre consórcios públicos, que a maior parte dos estudos sobre o tema aborda questóes particulares de cada caso como organização, modos de atuação no território abrangido e conflitos internos dessas organizaçóes. Este estudo, por possuir um recorte analítico transversal, em que se analisam os convênios entre os consórcios públicos e a União ao longo de um período de vinte anos (1996-2016), possibilitará que se compreenda, de forma mais aprofundada, a atuação dessas organizaçóes e o modo como elas se inserem nas diversas áreas de políticas públicas. 
$\mathrm{O}$ artigo está dividido em cinco partes, além desta introdução. Na seção 2, apresentamos um debate acerca dos municípios brasileiros e dos consórcios públicos. A seção 3 traz o enfoque teórico utilizado neste estudo, a partir da discussão sobre policy arenas. A seção 4 apresenta os procedimentos metodológicos do trabalho. $\mathrm{Na}$ seção 5 , são discutidos os dados relativos à celebração de convênios entre consórcios com a União na área de meio ambiente, resíduos sólidos, saneamento básico e agricultura. $\mathrm{Na}$ seção 6, são apresentadas as consideraçôes finais.

\section{A SITUAÇÃO DOS MUNICÍPIOS BRASILEIROS NO CONTEXTO FEDERATIVO}

O processo de descentralização político-administrativa que o Brasil vivenciou, principalmente a partir da década de 1980, colocou o município como uma peça-chave no jogo federativo, definindo-o como ente autônomo. Foi dada aos municípios a responsabilidade pelo desenvolvimento de inúmeras políticas públicas, sendo-lhes oferecida, contudo, restrita capacidade de arrecadação de recursos financeiros, apesar de haver previsão de transferência constitucional aos mesmos, como o Fundo de Participação dos Municípios (FPM). De forma geral, os entes subnacionais passaram a adquirir novas competências constitucionais na provisão de bens e serviços à população. Autores como Abrúcio, Franzese e Sano (2013), Lotta e Favaretto (2016) e Rocha (2016) esclarecem que o processo de descentralização surgiu como proposta alternativa ao regime autoritário e ao modo concentrado em que o poder se estabelecia no governo central.

Conforme apontam Arretche (2012) e Duarte et al. (2015), a descentralização, ocorrida após a Constituição Federal de 1988 (CF/1988), é entendida como uma estratégia de promover a participação social, reforçar o papel dos municípios e possibilitar mecanismos de controle social do Estado. Segundo os autores, os efeitos da descentralização das políticas públicas deixaram às claras a desigualdade de condiçóes políticas, administrativas, técnicas e financeiras dos municípios brasileiros, visto que a maioria deles é de pequeno porte e só dispóe de precárias ferramentas de gestão pública. Nesse sentido, os consórcios públicos surgem enquanto ferramentas que possibilitam aos municípios (principalmente os menores) acessar um conjunto de produtos e serviços que, individualmente, não teriam condiçóes de acessar. Segundo o Instituto Brasileiro de Geografia e Estatística (IBGE), o número de municípios brasileiros passou de 3.974, em 1980, para 5.570, em 2010 (IBGE, 2015). A maioria desses municípios é de pequeno porte: $44 \%$ possuem até $10 \mathrm{mil}$ habitantes, e $68 \%$ até 20 mil habitantes (IBGE, 2015). Com efeito, a literatura especializada aponta que esses municípios menores encontram sérias limitaçôes na construção de capacidades técnicas, administrativas e de arrecadação, bem como no desenvolvimento das políticas públicas (Grin, 2014). 
Arretche (2012) e Lotta, Gonçalves e Bitelman (2014) realizam uma análise sobre a condução de uma variedade de políticas públicas (saúde, educação, meio ambiente, saneamento básico, cultura, combate à pobreza, entre outras) ao longo das últimas décadas. As autoras apontam que, mesmo passadas décadas de descentralização, existe ainda uma forte presença do âmbito federal na condução das políticas públicas nos governos locais. Em todas as áreas de políticas públicas analisadas pelas autoras, foi identificada a centralidade do papel do governo central na proposição, normatização, financiamento, indução e coordenação das políticas e programas. Desse modo, podemos afirmar que, mesmo após a descentralização, a Uniâo continua sendo o ente que concentra a maior parte dos recursos arrecadados e pauta grande parcela da agenda das políticas públicas no Brasil.

A partir dos dados disponibilizados pela Pesquisa de Informaçóes Básicas Municipais (Munic)/IBGE, identificamos que 3.691 municípios brasileiros (66\% do total) participam de algum tipo de consórcio no Brasil (IBGE, 2015). Em relação à área de atuação dos consórcios, prevalece a da saúde; e quanto ao tamanho dos municípios consorciados, 70\% deles têm até 20 mil habitantes. De acordo com a mesma pesquisa, 97\% dos consórcios são intermunicipais; 9\%, dos municípios com o governo estadual; e $2 \%$, dos municípios com a União. Neste sentido, concordamos com Linhares, Messenberg e Ferreira (2017), quando identificam um expressivo aumento do número de municípios consorciados no país, após a promulgação da Lei Federal no 11.105 (Brasil, 2005), conhecida como a Lei dos Consórcios Públicos.

Portanto, identificam-se a centralidade e os constrangimentos dos municípios no cenário atual: por um lado, possuem status de entes federados e a incumbência de desenvolver instrumentos de planejamento a fim de orientar a implementação das políticas públicas em seus territórios; por outro, são altamente heterogêneos e desiguais, e possuem limitadas capacidades técnicas e operacionais (Rocha, 2016). Desse modo, a atuação dos consórcios públicos se torna ainda mais importante, tendo em vista as fragilidades políticas e operacionais dos municípios.

\section{OS CONSÓRCIOS NO BRASIL E SUA ATUAÇÃO DENTRO DAS POLICY ARENAS}

A literatura aponta que os consórcios públicos são espaços institucionais criados com o objetivo de auxiliar o município a ter acesso a um conjunto de produtos e serviços que, sozinho, não teria como conseguir (Strelec e Fonseca, 2011; Abrucio, Filippim e Dieguez, 2013; Machado e Andrade, 2014; Rocha, 2016). Essas organizações, quando criadas, decidem em que área vão atuar e se inserem em arenas de políticas públicas específicas (como no caso de consórcios de saúde, de meio ambiente, de resíduos sólidos e os voltados à agricultura, por exemplo), onde as 
regras do jogo já estão definidas por meio de regulamentações específicas. Desse modo, o desenvolvimento de açóes pelos consórcios está condicionado ao desenho institucional de cada campo de política pública em que esses se inserem. Essa ideia remete-se à seminal afirmação de Lowi (1972), "policy determines politics", que se mostra útil à compreensão do caso empírico aqui estudado. Além disso, apenas uma análise transversal dos consórcios públicos poderia permitir uma discussão à luz da teoria de Lowi (1972), tendo em vista o fato de que seria necessário analisar vários consórcios públicos simultaneamente. Dessa forma, analisar os convênios celebrados por estes com a União permitiu a observação da atuação de um conjunto variado de consórcios públicos em várias policy arenas.

A estrutura teórico-metodológica do artigo está inspirada no estudo de Lowi (1972) e de seus interlocutores contemporâneos como Frey et al. (2017), quando estes analisam e comparam o funcionamento de distintos tipos de políticas públicas brasileiras dentro dessa linha teórica e conceitual comum. Em sua análise, os autores identificam quais são os padrôes institucionais e processuais das diferentes políticas no contexto federativo brasileiro, a fim de conseguir comparar as distintas políticas públicas em seus campos de atuação.

Conforme Frey et al. (2017, p. 11):

Já Lowi (1972), distinguindo diferentes tipos de policies de caráter distributivo, redistributivo, regulatório e constitutivo - essas últimas correspondendo a políticas autorregulatórias ou políticas modificadoras das regra do jogo -, identifica, em função das reações e expectativas dos destinatários com relação às políticas, diferentes arenas políticas caracterizadas por processos peculiares de formaçáo de consenso e conflito em virtude justamente do tipo de política em questáo. Ou seja, dependendo do tipo de policy, as arenas políticas podem ser mais conflitivas - mais marcadas pelo enfrentamento ideológico - ou mais tendentes à busca de consenso.

Dessa forma, para este estudo sobre consórcios intermunicipais e suas distintas áreas de atuação, também procuramos entender como operam as diferentes áreas em que esses se inserem a partir de parâmetros comuns, como: i) quais são os principais marcos regulatórios dos campos de política pública e que efeitos eles têm sobre os objetivos dos convênios celebrados; ii) que efeitos a Lei dos Consórcios teve na celebração de convênios entre esses e União; e iii) que tipo de produtos e serviços os consórcios visam oferecer a partir desses acordos. A abordagem proposta por Lowi (1972) e Frey et al. (2017) mostrou-se frutífera para este estudo, ao permitir a análise das atividades dos consórcios por policy arena. Sendo assim, caracterizamos as policy arenas específicas, dando ênfase às estruturas de regulação (polity) e aos processos decisórios por essas condicionados (politics). 


\subsection{Apresentação das distintas policy arenas e de alguns de seus marcos regulatórios}

Em relação às políticas setoriais específicas discutidas neste estudo, ressaltamos que, na área do meio ambiente, há, desde a década de 1970, no Brasil, uma preocupação de consolidar um arcabouço institucional. Segundo Leme (2010), em 1974 é criada, no âmbito da Uniâo, a Secretaria Especial do Meio Ambiente, que, em 1992, foi elevada à condição de ministério. Além disso, data de 1981 a criação do Sistema Nacional do Meio Ambiente (Sisnama) e do Conselho Nacional do Meio Ambiente (Conama).

Identifica-se que o processo de descentralização por que o Brasil passou a partir da década de 1980 também teve efeitos sobre a área ambiental. No que concerne à atual implementaçáo de políticas ambientais e do cumprimento das obrigaçóes legais requeridas, Leme (2010) aponta que o município passou a ser o responsável pela implementação de um largo conjunto de políticas ambientais. Assim, ao passo que as leis e normativas ambientais são produzidas em nível federal, a sua implementação passou a ser de responsabilidade municipal. Além disso, o art. 225 da CF/1988 dispóe que todos os cidadãos brasileiros têm direito a um meio ambiente ecologicamente equilibrado e preservado. Segundo a autora, o arcabouço legal brasileiro vem buscando descentralizar as açôes do poder público, fortalecendo o papel dos municípios na gestão do meio ambiente.

Em relação às políticas de resíduos sólidos, é preciso apontar que tanto a Lei no 11.445 (Brasil, 2007), também conhecida como a Lei de Saneamento Básico, quanto a Lei no 12.305 (Brasil, 2010), também conhecida como Política Nacional de Resíduos Sólidos (PNRS), estabelecem que todas as cidades brasileiras devem elaborar os seus respectivos Planos Municipais de Saneamento Básico (PMSB) e seus Planos Municipais de Resíduos Sólidos (PMRS). As duas leis são marcos legais importantes para essa área específica de políticas públicas e postulam que a confecção dos referidos planos é condição necessária para o município receber os recursos da União a fim de executar açôes nessa área. A lei que institui a PNRS (Brasil, 2010) ainda diz que os municípios consorciados terão prioridade para o acesso aos recursos da Uniáo para a construçáo de sistemas de manejo de resíduos sólidos. Desse modo, a própria União cria um mecanismo de indução para a criação dos consórcios no Brasil nessa área e também cria uma obrigação institucional para os municípios brasileiros, a fim de que estes elaborem os referidos planos para essas áreas específicas (Maiello, Britto e Valle, 2018).

É importante ressaltar que a situação dos municípios brasileiros, no que diz respeito ao tratamento de resíduos sólidos, é bastante crítica. Simão, Dalmo e Nebra (2018) apontam que, em 2014, apenas 40,2\% dos municípios brasileiros realizavam a prática adequada de tratamento de resíduos sólidos urbanos, enquanto os outros 
$59,8 \%$ depositavam o lixo em espaços a céu aberto, em lixóes, onde não havia qualquer tipo de manejo adequado. Nesse sentido, para a maioria dos municípios brasileiros, seria inviável construir individualmente um sistema de manejo de resíduos sólidos. Dessa forma, a gestão regional, através de um consórcio, seria uma alternativa viável para os municípios no que concerne à gestão dos resíduos sólidos.

Em relação à área de agricultura, é importante apresentarmos o Sistema Unificado de Atenção à Sanidade Agropecuária (Suasa), promulgada pelo Decreto no 5.741 (Brasil, 2006). Esse sistema aponta que é de competência das prefeituras municipais a criação de seus próprios Serviços de Inspeção Municipais (SIMs). Esse sistema de inspeçâo é responsável por fiscalizar os estabelecimentos que industrializam produtos de origem animal e vegetal (tais como queijos, geleias, doces de frutas, embutidos, ovos, mel, carnes etc). De acordo com Grisa e Schneider (2014), o objetivo de criar a Suasa e o SIM foi agregar valor aos alimentos produzidos pela agricultura familiar e possibilitar que estes fossem comercializados posteriormente.

A Suasa também aponta que as prefeituras devem cumprir um determinado conjunto de requisitos técnicos e estruturais para fazer a fiscalização dos estabelecimentos. A legislação também diz que os produtos fiscalizados possuem comercialização restrita no espaço geográfico do órgão fiscalizador, ou seja, um produto fiscalizado pelo município de Campinas/SP, por exemplo, só poderá ser vendido no respectivo território municipal; e um produto fiscalizado por um órgão do governo do estado de Minas Gerais somente pode ser comercializado nesse estado. Ademais, a criação de um sistema de inspeção sanitária em um município de pequeno porte é inviável, devido aos custos de sua manutençâoo (médicos veterinários, laboratório de análises dos materiais, equipamentos etc.). Assim, uma das vantagens da inserção dos consórcios intermunicipais nesse campo é de que, desse modo, os municípios de menor porte teriam como possuir o SIM se este fosse organizado regionalmente.

As policy arenas apresentadas neste estudo são compostas por um conjunto de regras institucionais que produzem um efeito importante no desenho federativo. Em outras palavras, nas áreas de meio ambiente, de resíduos sólidos, de saneamento básico e de agricultura, o ente municipal passou a ser o principal ator responsável pelo processo de implementação das respectivas políticas, sem, contudo, possuir as capacidades técnicas e administrativas necessárias. Corroboramos a tese de Arretche (2012), que argumenta que o federalismo brasileiro apresenta como característica uma concentração de autoridade regulatória na União, cabendo aos municípios (que são altamente heterogêneos entre si) a implementação das políticas.

Dessa forma, os consórcios assumem, nesse jogo federativo, a função de serem instâncias de cooperação para que os municípios consigam implementar as políticas públicas. Além disso, é consenso na literatura sobre o tema que a maioria deles possui baixa capacidade técnica e financeira de cumprirem, por conta própria, todas 
as exigências relativas a cada campo de política pública, tais como a construção de um sistema adequado e completo de manejo de resíduos sólidos, de um serviço de inspeção do município, bem como condiçóes de elaboração de planos e relatórios técnicos (Grin, 2014; Fernandes, 2016; Marenco, Strohschoen e Joner, 2017; Grin, 2017). Assim, o estabelecimento de convênios entre os consórcios públicos e a União se apresenta como uma alternativa para que os consórcios busquem recursos para implementar açôes. Os dados apresentados a seguir possibilitarâo um aprofundamento da discussáo aqui elaborada, elucidando de que modo os consórcios se inserem em cada área de política pública.

\section{METODOLOGIA}

O estudo pode ser caracterizado como uma pesquisa exploratória, descritiva e documental, conforme indicam Marconi e Lakatos (1991), visto que apresenta indicadores e análises de escopo nacional, no sentido de obter os dados a fim de interpretá-los e compará-los, além de fornecer subsídios para futuras investigaçóes. Os achados permitiram examinar a evolução do acesso aos recursos financeiros por parte dos consórcios, bem como entender quais são suas principais áreas de atuação e aplicação.

Procuramos identificar as açóes desenvolvidas pelos consórcios públicos considerando os objetivos dos convênios celebrados entre estes e a União, no período 1996-2016. Entendemos que a celebração dos convênios é resultado da negociação política dos consórcios intermunicipais com o governo central, ou seja, os convênios são provenientes da iniciativa dos consórcios e presumem a existência de um consenso entre os municípios membros.

Para a coleta de dados, foi acessado o Portal da Transparência de Recursos Federais da União, cuja extração ocorreu em setembro de 2017. Diferentemente da maioria das pesquisas sobre consórcios públicos no país, que são baseadas em estudos de caso, este trabalho propóe um desenho de caráter transversal. O nosso foco principal foi obter os dados, a fim de interpretá-los e compará-los, com o intuito, também, de fornecer subsídios para futuras investigaçôes.

Foi realizada análise do conteúdo dos convênios que estavam disponibilizados no Portal da Transparência, com base na proposta metodológica de Bardin (2011), que destaca a materialidade linguística e o conteúdo do texto. Os documentos analisados são peças-chave do processo de transferência de recursos, visto que apresentavam os objetivos e as justificativas para a celebraçâo de convênios entre os consórcios e a Uniáo.

O Portal da Transparência da União oferece mais detalhes dos convênios estabelecidos a partir de 2008, pois os firmados anteriormente não trazem uma descrição aprofundada do objetivo e da justificativa da proposta direcionada à obtenção de recursos. Desse modo, nos casos anteriores àquele ano, não foi possível analisar com muita profundidade o conteúdo dos convênios estabelecidos. 


\section{DESCRIÇÃO GERAL DOS CONVÊNIOS CELEBRADOS NO BRASIL}

$\mathrm{Na}$ sequência, examinaremos os dados da seguinte forma: primeiramente a evolução da celebração de convênio entre União e consórcios intermunicipais no Brasil entre 1996 e 2016, apresentando um panorama geral dos consórcios públicos nos país. Em seguida, analisaremos o conteúdo das propostas apresentadas pelos consórcios nas áreas de meio ambiente, resíduos sólidos e saneamento básico e agricultura. Concomitante à apresentação dos dados, vamos discuti-los à luz dos debates apresentados sobre federalismo e policy arenas.

O gráfico 1 mostra a distribuição do número de convênios firmados com consórcios ao longo do tempo. Identificamos que, após a aprovação da Lei dos Consórcios, em 2005, o número de convênios estabelecidos entre os consórcios e a União aumentou significativamente, principalmente em 2010 e 2011. Todavia, houve uma distribuição irregular ao longo da série histórica. Ao todo, somam-se 407 convênios.

\section{GRÁFICO 1}

Evolução da celebração de convênios entre a União e consórcios intermunicipais Brasil (1996-2016)

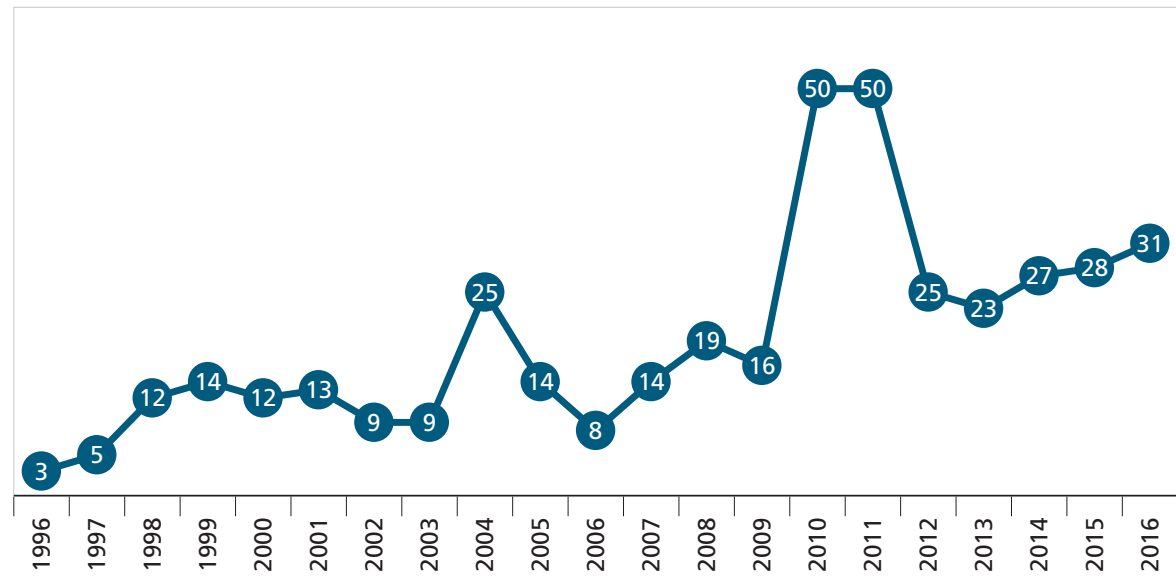

Fonte: Portal da Transparência da União. Disponível em: <https://bit.ly/2HDEJMk>. Elaboração dos autores.

O gráfico 2 apresenta a porcentagem da concentração dos convênios celebrados entre os consórcios e a União, conforme as áreas relativas. Identifica-se que, dos convênios celebrados no período 1996-2016, a maioria deles (31,8\%; 122 no total) tinha a intenção de promover políticas na área da saúde. Somados, os convênios voltados ao meio ambiente, manejo de resíduos sólidos, saneamento básico e agricultura concentraram 41,4\% (29 convênios de saneamento básico, 76 voltados à agricultura e 17 voltados ao meio ambiente) do total dos celebrados pelos consórcios com a União no período estudado. 
GRÁFICO 2

Convênios celebrados pelos consórcios com a União conforme a área temática - Brasil (1996-2016)

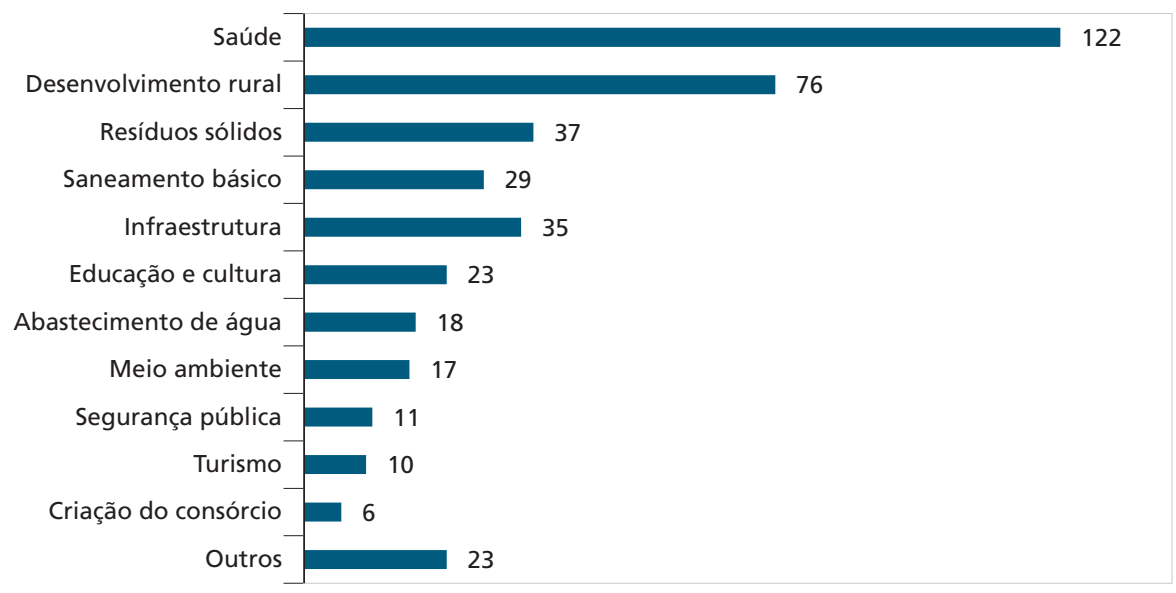

Fonte: Portal da Transparência da União. Disponível em: <https://bit.ly/2G3pRpO>. Elaboração dos autores.

\subsection{Convênios na área de meio ambiente, saneamento básico e resíduos sólidos}

Identificamos que há um conjunto amplo de atividades que os consórcios públicos intermunicipais realizam na área de meio ambiente, saneamento básico e gestão de resíduos sólidos, e que, para isso, celebraram convênios com a União para captar recursos. A partir da análise de conteúdo das propostas que embasaram os convênios entre consórcios e União, os respectivos objetivos foram organizados nas seguintes áreas: construção de aterro sanitário e usina de reciclagem; elaboração do Plano de Gestáo Integrada de Resíduos Sólidos; elaboração do Plano de Saneamento Básico; recuperação de bacia hidrográfica; cadastramento de usuários de recursos hídricos; implantação do sistema de resíduos sólidos; educação ambiental; ação de controle da qualidade água; e execução da política de resíduos sólidos e saneamento.

No gráfico 3, observamos a frequência dos 83 objetivos identificados. 
GRÁFICO 3

Objetivos dos convênios, em números absolutos, relacionados à área de meio ambiente, gestão de resíduos sólidos e saneamento básico, celebrados entre os consórcios e a União, por tipo - Brasil (1996-2016)

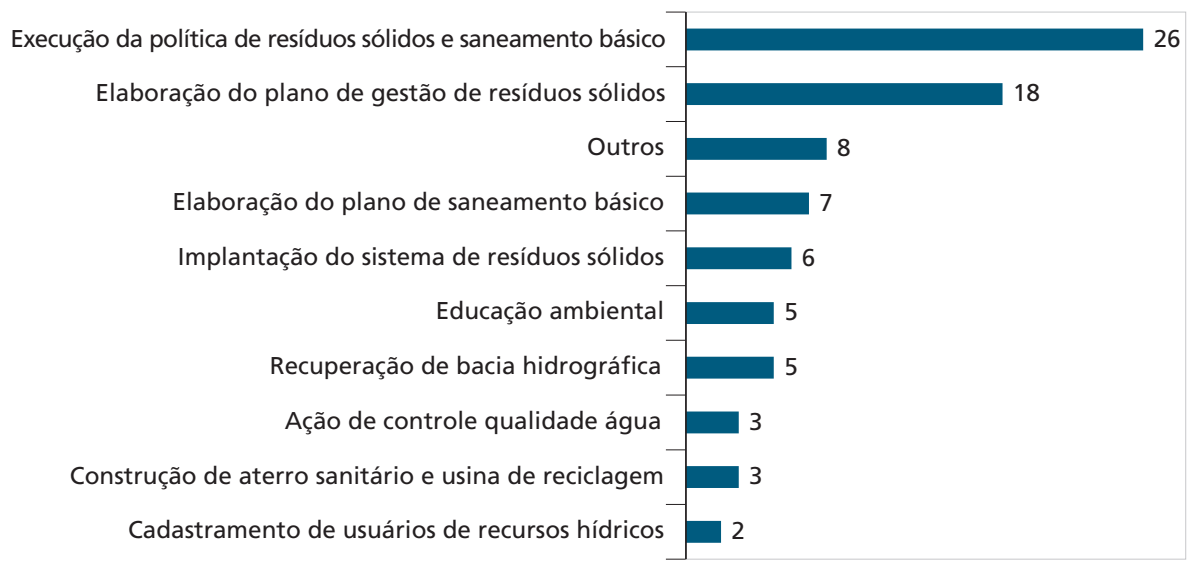

Fonte: Portal da Transparência da União. Disponivel em: <https://bit.ly/3e9Wa3a>.

No que concerne aos dados analisados, identificamos que a elaboraçáo dos Planos Municipais de Saneamento Básico e dos Planos Municipais de Resíduos Sólidos estão entre as principais atividades realizadas pelos consórcios, totalizando 25 objetivos (30\% do total). Como foi apontado, a Política Nacional de Saneamento Básico e a Política Nacional de Resíduos Sólidos estabelecem que os municípios devem elaborar os referidos planos municipais. Sem a elaboração desses, não há como o ente municipal acessar os recursos da União para a implementação das referidas políticas. Todavia, a confecção de planos municipais, tanto de resíduos sólidos quanto de saneamento básico, exige um conjunto de capacidades técnicas (tais como a contratação de geógrafos, biólogos, ambientalistas, engenheiros) que os municípios, em sua maioria, não possuem. Assim, a partir do convênio, o consórcio teria recursos para contratar os profissionais adequados para a elaboração dos referidos planos municipais. Desse modo, os consórcios constituem-se como entes que possibilitam que esses planos sejam produzidos e ofertados para os municípios consorciados.

No caso da gestão de resíduos sólidos, em específico, a vinculação do município a um consórcio é ainda mais importante, porque a política nacional determina que os consórcios tenham prioridade ao acesso de recursos públicos da União. Dessa forma, a União, através da PNRS, fortalece a gestão integrada dos resíduos e propóe medidas de incentivos para a formação dessas organizaçóes. Maiello, Britto e Valle (2018) questionam, observando o conjunto de exigências que a PNRS faz para os municípios brasileiros, qual seria a capacidade desses entes de atenderem 
às determinaçóes da Lei Nacional. Os autores ainda apontam que muitos municípios brasileiros encontram dificuldades quase insolúveis de planejar e promover isoladamente a implementação da política. Por isso, torna-se necessária a gestão regionalizada, para a superação das deficiências estruturais, a redução dos custos no sistema de coleta e tratamento e a obtenção de ganhos de escala.

A partir da análise qualitativa do conteúdo dos convênios estabelecidos com a União, foi possível identificar que alguns consórcios visam estabelecer uma gestão integrada de resíduos sólidos, ou seja, propóem que membros do consórcio trabalhem conjuntamente em nível regional com essa política. Constatamos que $35 \%$ dos convênios celebrados na área do meio ambiente, gestão de resíduos sólidos e saneamento básico firmados no período 1996-2016 tinham como objetivo financiar açôes voltadas à construçáo de aterros sanitários ou usinas de reciclagem pelos próprios consórcios. Neste caso, além de elaborar os planos de resíduos sólidos, um conjunto de consórcios apresenta-se como executor da política pública, organizando recursos e demandas no território. Desse modo, além das atividades de planejamento, observamos que uma parcela dos convênios celebrados é proposta de execução de atividades, ou seja, alguns consórcios implementam açóes relacionadas à reciclagem e à gestáo de resíduos sólidos, prestando diretamente os serviços concernentes

$\mathrm{Na}$ análise dos projetos submetidos, observamos um caso que ilustra a importância do consórcio enquanto uma organização que permite aos municípios consorciados acessarem um conjunto de benefícios. O Consórcio Intermunicipal da Serra Catarinense, sediado em Lages/SC, conseguiu firmar dezesseis convênios com a União entre 2010 e 2011 . As propostas submetidas buscavam realizar a implantação e a melhoria no sistema de esgotamento sanitário nos municípios da região serrana de Santa Catarina, atendendo a cidades com menos de 50 mil habitantes que possuíam projetos nesse âmbito. É interessante identificar que, em todas as dezesseis propostas, o objetivo e a justificativa eram iguais, salvo o nome do município que receberia o recurso. Nesse caso, o consórcio submeteu um projeto para cada município consorciado, cujo valor do convênio variou entre $\mathrm{R} \$$ 432.552,63 e R \$2.200.000,00. Assim, o consórcio conseguiu recursos para que os municípios implantassem os sistemas de esgotamento sanitário dentro de seus territórios, demonstrando o potencial de articulação política dos municípios para obter recursos. Identifica-se, desse modo, que o consórcio atua como um mediador político, visto que aglutina os interesses dos prefeitos com vistas à captação de recursos - tais como emendas parlamentares e fundos específicos dos ministérios.

Em relação à fonte de recursos, identificamos que o Ministério da Saúde (MS) é o principal financiador dos convênios celebrados entre consórcios intermunicipais da área de meio ambiente, resíduos sólidos e saneamento básico do Brasil, através 
da Fundação Nacional de Saúde (Funasa). ${ }^{4}$ Identificou-se que o MS financiou $51,80 \%$ dos convênios voltados para a área do meio ambiente, saneamento básico e gestáo de resíduos sólidos, celebrados no período 1996-2016, enquanto que o Ministério do Meio Ambiente foi responsável por 34,93\%, e o extinto Ministério das Cidades, por $10,84 \%$ do total desses acordos.

Em relação à análise da celebração dos convênios entre os consórcios intermunicipais com a Uniâo segundo a Unidade da Federação (UF), identificamos que há uma preponderância dos estados da região Sul e Sudeste diante dos demais. Os consórcios de Santa Catarina apresentam um destacado interesse em celebrar convênios na área de meio ambiente, resíduos sólidos e saneamento básico, conforme identificado no gráfico 4 .

GRÁFICO 4

Número de convênios celebrados na área do meio ambiente, saneamento básico e gestão de resíduos sólidos, por UF - Brasil (1996-2016)

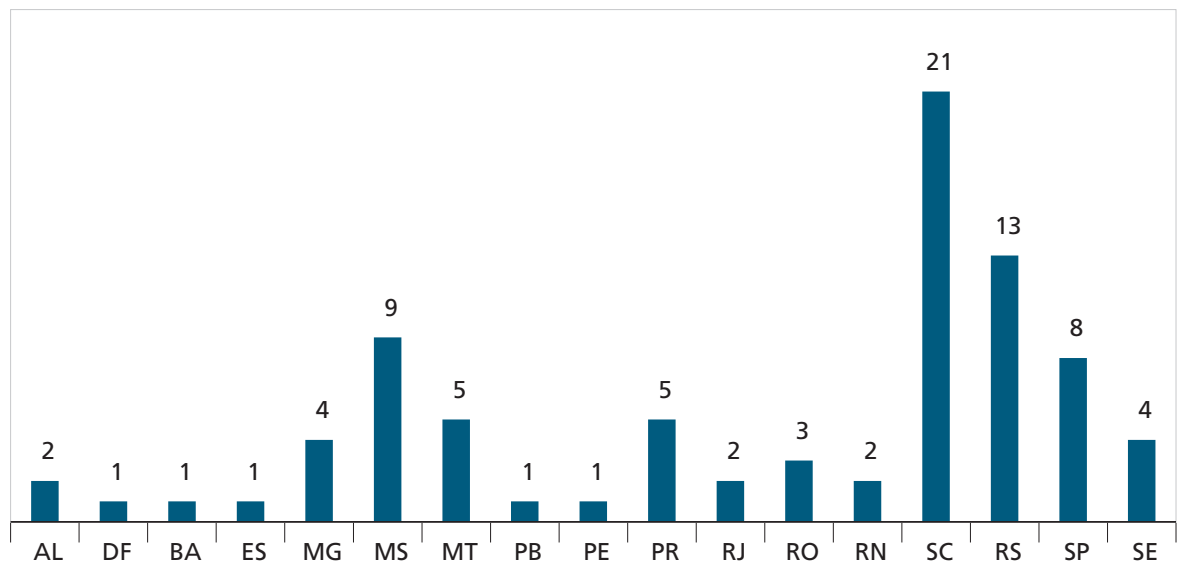

Fonte: Portal da Transparência da União.

O estudo de Meireles (2019), relativo à lógica das transferências voluntárias da União aos municípios, destaca que elementos como pressão política, partidos políticos e barganha são determinantes no processo de obtenção de recursos voluntários da União, categoria na qual se enquadram os convênios com os consórcios, como já mencionado acima. Desse modo, pode-se averiguar que a capacidade dos consórcios em captar recursos voluntários da União é distribuída de forma desigual pelo território. Nesse sentido, estudos posteriores poderão aprofundar o processo de barganha política que permeia o estabelecimento dos convênios.

4. A Funasa tem como objetivo promover a saúde pública e a inclusão social por meio de ações de saneamento e saúde ambiental. 
Em relação ao ano de estabelecimento dos convênios na área de meio ambiente, saneamento básico e gestão de resíduos sólidos, identificamos (gráfico 5) que a instituição da Política Nacional de Resíduos Sólidos, aprovada em 2010, produziu um efeito imediato e pontual no aumento da celebração de convênios entre consórcios públicos e a União. Verifica-se que o número de convênios dobrou no ano da aprovação da lei e dobrou novamente no ano seguinte. Contudo, a tendência de aumento náo é identificada nos anos seguintes.

\section{GRÁFICO 5}

Quantidade de convênios celebrados por ano referente à área de meio ambiente, gestão de resíduos sólidos e saneamento básico - Brasil (1996-2016)

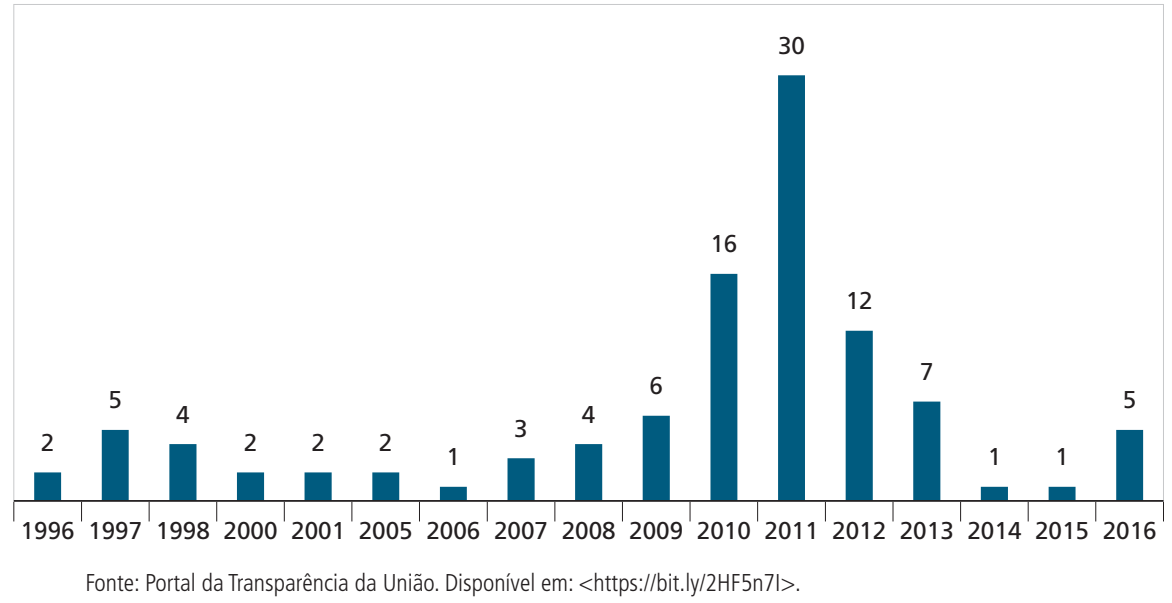

Nesse sentido, percebe-se, nessa arena de políticas, um mecanismo de indução da União para a criação dos consórcios, visto que estes são prioritários para a captação de recursos destinados à gestão de resíduos sólidos conforme propóe a lei. Desse modo, identifica-se que, enquanto a Lei dos Consórcios Públicos, aprovada em 2005, não impactou no aumento da celebração dos convênios na área do meio ambiente, gestão de resíduos sólidos e saneamento básico no Brasil, a Política Nacional de Resíduos Sólidos criou um mecanismo de enforcement para o estabelecimento de convênios com a União via consórcios. Ou seja, dado o fato de que teriam prioridade no acesso aos recursos, se consorciados, vários municípios aproveitaram essa oportunidade de atuar de forma consorciada nessa área de política pública. 


\subsection{Desenvolvimento rural e agricultura}

Identificamos que 19,8\% dos convênios celebrados pelos consórcios com a União visavam desenvolver políticas de desenvolvimento rural, especialmente na área de agricultura. Identificamos que muitos convênios dessa área tinham como objetivo adequar os municípios ao Suasa. Nesse caso, os consórcios tinham como meta buscar financiamento para equipar os profissionais que trabalham com vigilância sanitária a inspecionar os produtos de origem animal e vegetal nos municípios consorciados. Portanto, assim como na área do meio ambiente, saneamento básico e resíduos sólidos, os consórcios estáo preocupados em adequar os municípios às legislaçóes federais vigentes.

A partir da análise de conteúdo dos 76 convênios, celebrados entre 1996 e 2016 entre consórcios intermunicipais e a União, que tinham como intuito realizar políticas na área da agricultura, identificou-se que 38 deles tinham como objetivo promover a comercialização dos projetos oriundos da agricultura, em alguns casos oferecendo apoio logístico ou promovendo o estabelecimento de feiras para comercialização. Também se encontravam, entre os objetivos dos convênios, a construção de uma estrutura de fiscalização dos produtos e incentivo aos produtores para que sigam as normativas de vigilância sanitária. Além disso, dezenove convênios tinham como objetivo fornecer assistência técnica e serviços de inspeção sanitária para os empreendimentos que fabricavam produtos de origem animal.

Em todos esses dezenove casos, no corpo do texto dos projetos enviados pelos consórcios à Uniáo como justificativa para a captação dos recursos, identifica-se a preocupação de adequar os municípios abrangidos pelos consórcios às normativas legais que institui a Suasa. Desse modo, os consórcios propunham açóes no sentido de criar uma equipe regional para a fiscalização dos produtos de origem vegetal ou animal, bem como providenciar a estrutura técnica e operacional para o trabalho de fiscalização.

De forma ilustrativa, podemos citar o caso do Consórcio Intermunicipal de Desenvolvimento Sustentável da Microrregiấo da Serra Geral de Minas Gerais, que celebrou, em 2015, um convênio com o Ministério do Desenvolvimento Agrário visando "sanar a falta de padrão entre as diversas agroindústrias (...) o que dificulta a identificação de alguns dos produtos de nossa regiáo e a sua aceitação, inclusive pelo mercado institucional", com vista à "certificação da produção da agroindústria familiar para acabar com o comércio clandestino, principalmente do queijo mineiro" (Brasil, 2018). Dessa forma, o convênio estabelecido propôs-se a estruturar uma Coordenadoria Regional de Inspeção Sanitária do referido consórcio, com o aporte de veículos, material de laboratório e outros equipamentos para atuação de uma equipe de profissionais. 
O gráfico 6 apresenta o número e os objetivos dos convênios voltados para a área do desenvolvimento rural e agricultura. Ele revela que uma importante parcela dos convênios objetivava promover açóes voltadas à piscicultura e à compra de maquinários (escavadeiras hidráulicas, tratores etc.) para a manutenção de estradas vicinais localizadas nas áreas rurais dos municípios. Desse modo, os consórcios também se interessam em adquirir esses maquinários, os quais, em geral, apresentam um alto custo de compra, mas que, de forma consorciada, tornam-se acessíveis aos municípios.

\section{GRÁFICO 6}

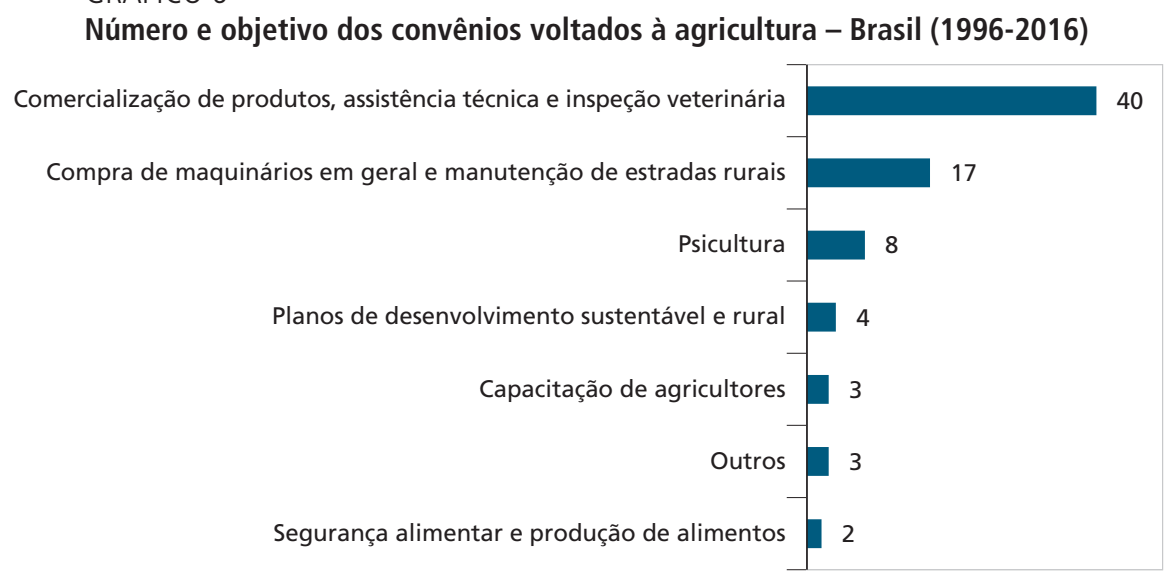

Fonte: Portal da Transparência da União. Disponível em: <https://bit.ly/3mtQwvs>.

Em relação ao órgão financiador dos convênios relacionados à área de agricultura e desenvolvimento rural, constatamos que o Ministério do Desenvolvimento Agrário, o Ministério da Agricultura, Pecuária e Abastecimento, o Ministério da Integração Nacional e o Ministério do Desenvolvimento Social são os principais responsáveis pelo financiamento.

Em relação à distribuição dos convênios por UF, identificamos que os consórcios localizados nos estados da regiáo Sul concentraram a metade dos convênios destinados às políticas relacionadas com a agricultura e o desenvolvimento rural (39 convênios, no total). Em contrapartida, na regiấo Sudeste, apenas o estado de São Paulo apresentou um convênio nessa área. Chama a atenção que a região Centro-Oeste, mais especificamente os estados de Mato Grosso, Goiás e Mato Grosso do Sul, que até então demonstravam dados inexpressivos para as outras políticas públicas, apresentaram $20 \%$ dos convênios destinados à área em análise. Os consórcios situados em estados como Rio Grande do Norte, Alagoas, Pernambuco e Bahia propuseram convênios com o objetivo de desenvolver políticas voltadas principalmente para a questão de segurança alimentar, incentivo ao plantio de alimentos e açôes de combate à fome e à desnutrição. 
Desse modo, ao analisar o conteúdo dos convênios, voltamos novamente aos argumentos de Arretche (2012), Grin $(2014 ; 2017)$ e Lima et al. (2020) sobre o fato de que, a partir da CF/1988, os municípios brasileiros passaram a assumir cada vez mais responsabilidades e funçóes, sem necessariamente possuírem a competência técnica e os recursos para exercê-las. Os consórcios públicos intermunicipais passaram a atuar em um conjunto de áreas de políticas públicas, para além da saúde, na qual eram tradicionalmente situados (Lima, 2000; Amaral e Blatt, 2011). Assim, essas organizaçôes passaram a desenvolver açôes em outras áreas, como gestáo de políticas de meio ambiente, de resíduos sólidos, de saneamento básico e de agricultura. A literatura aponta que, a partir da atuação de um consórcio público, os municípios criariam uma estrutura de gestão que lhes possibilitaria acessar um conjunto de serviços que, individualmente, poderiam não ter condiçốes de possuir. Ademais, os dados oferecidos pela pesquisa Munic/ IBGE apontam que a maioria dos municípios brasileiros possuem menos de 20 mil habitantes (IBGE, 2015). Desse modo, a partir dos dados apresentados, observamos que os consórcios seriam uma ferramenta para viabilizar aos municípios brasileiros o acesso a um conjunto de produtos e serviços. Os convênios analisados são um importante indicativo de que esses consórcios, ao longo das últimas décadas, já possuem uma estrutura institucional que lhes permite articular os interesses locais em torno de pautas específicas e buscar os recursos para implementar suas políticas.

Do ponto de vista da coordenação federativa, identifica-se que os consórcios públicos se constituem enquanto instâncias regionais que articulam os interesses locais e conciliam esforços para a busca de recursos, tendo em vista a implementação de políticas públicas. O desenho do estudo, a partir de um recorte transversal, possibilitou identificar as principais temáticas de atuação dos consórcios por meio dos convênios realizados entre estes e a União. Conforme apontam Abrúcio e Segatto (2016), historicamente os estudos sobre coordenaçáo federativa no Brasil deram mais atenção ao modo como a esfera federal induz o processo de desenvolvimento das políticas públicas com os demais entes federados. Na esteira deste entendimento, neste trabalho investigamos como os entes subnacionais operam a implementação de políticas públicas.

Constatamos que os consórcios públicos orientam as suas atividades de acordo com as regras do jogo das respectivas arenas de políticas públicas em que se inserem. Desse modo, o conceito de policy arenas, proposto por Lowi (1972) e trabalhado por Frey et al. (2017), mostrou-se útil para a análise. A partir da discussão sobre a situação dos municípios no jogo federativo, conseguimos identificar que os consórcios atuam no sentido de contribuir com a amenização das fragilidades técnicas e institucionais dos municípios, dando a eles condiçóes de acesso a produtos e serviços. Além disso, do ponto de vista da consolidação de um modo 
de governança regional de políticas públicas, os consórcios públicos apresentam-se como boas ferramentas - tanto na parte da articulação políticas com os entes centrais quanto para a implementação de políticas públicas.

\section{CONSIDERAÇÕES FINAIS}

A partir dos dados analisados, pode-se concluir que os convênios estabelecidos pelos consórcios públicos com a União dialogam diretamente com cada policy arena apresentada neste estudo. Dessa forma, dada a sua ampla inserção e relevância para os municípios, os consórcios públicos podem ser considerados importantes atores do jogo federativo na implementação de políticas públicas.

Neste estudo, foram apresentados alguns marcos regulatórios dos campos de cada área de política pública, evidenciando o fato de que os municípios são os entes responsáveis pela implementação de um conjunto de produtos e serviços e de que forma os convênios estabelecidos pelos consórcios públicos com a União dialogam com esse arcabouço institucional. Conclui-se, a partir dos convênios estabelecidos com a União propostos pelos consórcios públicos, que os municípios conseguem ter acesso a um conjunto de produtos e estruturas necessárias à produção de políticas públicas, tais como: o Sistema de Inspeçâo Municipal, os Planos Municipais de Resíduos Sólidos, o Plano Municipal de Saneamento Básico e o Sistema de coleta e gestão de resíduos sólidos.

Identificamos que, no caso dos consórcios voltados ao meio ambiente, saneamento básico e resíduos sólidos, a Política Nacional de Resíduos Sólidos cria um mecanismo de enforcement, ao priorizar os municípios consorciados no que concerne à transferência de recursos, como foi demonstrado pelo aumento do número de convênios celebrados entre os consórcios públicos e a União a partir de 2010.

De modo geral, o artigo aponta que a autonomia dos municípios para participarem de consórcios é vital no desenvolvimento das suas atividades. Os dados reiteram o argumento proposto por Arretche (2012) em relação aos efeitos do papel predominante da Uniáo, enquanto produtora de normas institucionais, sobre os municípios brasileiros. Todavia, identificamos que, por meio dos consórcios, os municípios têm a possibilidade de se adequar às normativas federais e viabilizar a implementação de um conjunto de políticas públicas.

Futuras agendas de pesquisas poderão investigar de que forma os consórcios constroem suas estratégias de barganha política para captar recursos, conforme demonstrado no estudo de Meireles (2019). Além disso, é interessante aprofundar a discussão dos consórcios em relação aos órgãos fiscalizados, tais como os tribunais de contas ou conselhos e comitês participativos (Almeida e Tatagiba, 2012; Leal e Lui, 2018; Lino e Aquino, 2020), para se identificar como se dão as relaçóes institucionais entre sociedade civil, agentes fiscalizadores e gestores. 


\section{REFERÊNCIAS}

ABRUCIO, F. L. A coordenação federativa no Brasil: a experiência do período FHC e os desafios do governo Lula. Revista de Sociologia e Política, n. 24, p. 41-67, 2005.

ABRUCIO, F. L.; FILIPPIM, E. S.; DIEGUEZ, R. C. Inovação na cooperação intermunicipal no Brasil: a experiência da Federação Catarinense de Municípios (Fecam) na construção de consórcios públicos. Revista de Administração Pública, v. 47, n. 6, p. 1543-1568, 2013.

ABRUCIO, F. L.; FRANZESE, C.; SANO, H. Trajetória recente da cooperação e coordenação no federalismo brasileiro: avanços e desafios. In: JUNIOR CARDOSO, J. C.; BERCOVICI, G. (Orgs.). República, democracia e desenvolvimento: contribuiçóes ao Estado brasileiro contemporâneo. Brasília: Ipea, 2013.

ALMEIDA, C.; TATAGIBA, L. Os conselhos gestores sob o crivo da política: balanços e perspectivas. Serv. Soc. Soc., São Paulo, n. 109, p. 68. 2012.

AMARAL, S. M. S.; BLATT, C. R. Consórcio intermunicipal para a aquisição de medicamentos: impacto no desabastecimento e no custo. Revista de Saúde Pública, v. 45, n. 4, p. 799-801, 2011.

ARRETCHE, M. Federalismo e políticas sociais no Brasil: problemas de coordenação e autonomia. Sáo Paulo em Perspectiva, v. 18, n. 2, p. 17-26, 2004.

. Democracia, federalismo e centralizaçáo no Brasil. Rio de Janeiro: Editora Fiocruz /FGV, 2012.

BARDIN, L. Análise de conteúdo. Lisboa: Ediçōes 70, 2011.

BOTTI, C. S. et al. Regionalização dos serviços de saúde em Mato Grosso: um estudo de caso da implantação do Consórcio Intermunicipal de Saúde da Regiáo do Teles Pires, no período de 2000 a 2008. Epidemiologia e Serviços de Saúde, v. 22, n. 3, p. 491-500, 2013.

BRASIL. Decreto no 5.741, de 30 de março de 2006. Sistema Unificado de Atençáo à Sanidade Agropecuária, e dá outras providências. Diário Oficial da Uniáo, Brasília, 31 mar. 2006. Disponível em: <https://bit.ly/3ea3egc>. Acesso em: jun. 2018.

. Lei no 11.107, de 6 de abril de 2005. Dispóe sobre normas de contratação de consórcios públicos e dá outras providências. Diário Oficial da Uniáo, Brasília, 7 abr. 2005. Disponível em: <https://bit.ly/2Jc7jVI>.

. Ministério da Saúde. Portaria MS/GM no 399, de 22 de fevereiro de 2006. Divulga o Pacto pela Saúde 2006 - Consolidação do SUS, e aprova as Diretrizes Operacionais do referido pacto. Diário Oficial da Uniáo, Brasília, 22 fev. 2006. 
. Lei no 11.445 , de 5 de janeiro de 2007. Estabelece as diretrizes nacionais para o saneamento básico; cria o Comitê Interministerial de Saneamento Básico; altera as leis no 6.766 , de 19 de dezembro de $1979,8.666$, de 21 de junho de 1993 , e 8.987, de 13 de fevereiro de 1995; e revoga a Lei no 6.528 , de 11 de maio de 1978. (Redação pela Lei no 14.026 , de 2020). Diário Oficial da Uniáo, Brasília, 6 jan. 2007. Disponível em: <https://bit.ly/2HDkZrV>. Acesso em: 18 maio 2018.

. Lei no 12.305, de 2 de agosto de 2010. Institui a Política Nacional de Resíduos Sólidos. Diário Oficial da Uniáo, Brasília, 3 ago. 2010. Disponível em: $<$ https://bit.ly/3jtBq7q>. Acesso em: 15 jun. 2018.

. Portal da Transparência dos Recursos Federais. Ministério da Transparência e Controladoria-Geral da União. Portal da Transparência. Brasília: Portal da Transparência; MT; CGU, 2018. Disponível em: <https://bit.ly/35DHTrE>. Acesso em: 15 jun. 2018.

COUTO, C. G.; BELLON, G. L. A. Imitação ou coerção? Constituições estaduais e centralização federativa no Brasil. Revista de Administraçáo Pública, v. 52, n. 2, p. 321-344, 2018.

DUARTE, L. S. et al. Regionalização da saúde no Brasil: uma perspectiva de análise. Saúde e Sociedade, v. 24, n. 2, p. 472-485, 2015.

FERNANDES, F. S. Capacidade institucional: uma revisão de conceitos e programas federais de governo para o fortalecimento da administração pública. Cadernos EBAPE.BR, v. 14, n. 3, p. 695-704, 2016.

FREY, K. et al. Políticas públicas em perspectiva comparada: proposta de um framework para a análise de experiências locais. Revista do Serviço Público, v. 68, n. 1, p. 9-36, 2017.

GRIN, E. J. Trajetória e avaliação dos programas federais brasileiros voltados a promover a eficiência administrativa e fiscal dos municípios. Revista de Administraçáo Pública, v. 48, n. 2, p. 459-480, 2014.

. O que dizer das capacidades estatais dos municípios brasileiros em um contexto de descentralização de políticas? In: CONFERENCE: CONGRESO NACIONAL DE CIENCIA POLÍTICA, 13., 2017, Buenos Aires, Argentina. Anais... Buenos Aires: Universidad Torquato di Tella, 2017.

GRISA, C.; SCHNEIDER, S. Três geraçôes de políticas públicas para a agricultura familiar e formas de interação entre sociedade e estado no Brasil. Revista de Economia e Sociologia Rural, v. 52, p. 125-146, 2014. 
IBGE - INSTITUTO BRASILEIRO DE GEOGRAFIA E ESTATÍSTICA. Pesquisa de Informaçóes Básicas Municipais - Munic: perfil dos municípios brasileiros. Rio de Janeiro: IBGE, 2015.

LEAL, A. F.; LUI, L. Instituições participativas e seus efeitos nas políticas públicas: estudo do Comitê de Mortalidade por Aids de Porto Alegre. Saúde e Sociedade. v. 27, n. 1, p. 94-105, 2018. Disponível em: <https://bit.ly/3kDmsgv>. Acesso em: 25 out. 2018 .

LEME, T. N. Os municípios e a Política Nacional do Meio Ambiente. Planejamento e Políticas Públicas, v. 2, n. 35, 2010. Disponível em: <https://bit.ly/37N20Gk>. Acesso em: 25 out. 2018.

LIMA, A. P. G. Os consórcios intermunicipais de saúde e o Sistema Único de Saúde. Cadernos de Saúde Pública, v. 16, n. 4, p. 985-996, 2000.

LIMA, L. L. et al. Planejamento governamental nos municípios brasileiros: em direção a uma agenda de pesquisa. Cad. EBAPE.BR, Rio de Janeiro, v. 18, n. 2, p. 323-335, jun. 2020.

LINHARES, P. T. F. S.; MESSENBERG, R. P.; FERREIRA, A. P. L. Transformaçóes na federaçáo brasileira: o consórcio intermunicipal no Brasil do início do século XXI. Brasília: Ipea, 2017. Disponível em: <https://bit.ly/3kBmSE2>. Acesso em: 12 set. 2018.

LOTTA, G.; FAVARETO, A. Desafios da integração nos novos arranjos institucionais de políticas públicas no Brasil. Revista de Sociologia e Política, v. 24, n. 57, p. 49-65, 2016.

LOTTA, G. S.; GONÇALVES, R.; BITELMAN, M. A Coordenação Federativa de Políticas Públicas: uma análise das políticas brasileiras nas últimas décadas. Cadernos Gestáo Pública e Cidadania, v. 19, n. 64, 2014. Disponível em: <https:// bit.ly/31KA6XB>. Acesso em: 25 out. 2018.

LOWI, T. J. Four Systems of Policy, Politics, and Choice. Public Administration Review, v. 32, n. 4, p. 298-310, 1972.

LINO, A. F; AQUINO, A. C. B. Práticas não adequadas nos tribunais de contas. Revista de Administraçáo Pública, v. 54, n. 2, p. 220-242, 2020.

LUI, L. Cooperação interfederativa e regionalização da saúde: a atuação dos consórcios intermunicipais no Rio Grande do Sul. In: CARNEIRO, J. M. B.; BRITO, E. S. (Orgs.). Consórcios Intermunicipais e Políticas Públicas Regionais. São Paulo: Oficina Municipal; Fundação Konrad Adenauer, 2019. 
LUI, L.; SCHABBACH, L. M. Cooperação intergovernamental e consórcios públicos: uma análise da celebração de convênios. Ciências Sociais Unisinos, v. 56, n. 1, p. 13-25, 2020.

MACHADO, J. A.; ANDRADE, M. L. C. Cooperação intergovernamental, consórcios públicos e sistemas de distribuição de custos e benefícios. Revista de Administraçáo Pública, v. 48, n. 3, p. 695-720, 2014.

MAIELLO, A.; BRITTO, A. L. N. P.; VALLE, T. F. Implementação da Política Nacional de Resíduos Sólidos. Revista de Administraçáo Pública, v. 52, n. 1, p. 24-51, 2018.

MARCONI, M. A.; LAKATOS, E. M. Técnicas de Pesquisa. São Paulo: Atlas, 1991. MARENCO, A.; STROHSCHOEN, M. T. B.; JONER, W. Capacidade estatal, burocracia e tributação nos municípios brasileiros. Revista de Sociologia e Política, v. 25, n. 64, p. 3-21, 2017.

MEIRELES, F. Alinhamento partidário e demanda por transferências federais no Brasil. Revista de Administraçáo Pública. v. 53, n. 1, p. 173-94, 2019.

MORAIS, V. S.; CHAVES, A. P. L. Percepção dos gestores municipais de saúde relacionada à saúde ambiental: consórcio intermunicipal de saúde Cerrado Tocantins Araguaia. Saúde e Sociedade, v. 25, p. 349-360, 2016.

NICOLETTO, S. C. S.; CORDONI JÚNIOR, L.; COSTA, N. R. Consórcios Intermunicipais de Saúde: o caso do Paraná, Brasil. Cadernos de Saúde Pública, v. 21, n. 1, p. 29-38, 2005.

ROCHA, C. V. A cooperação federativa e a política de saúde: o caso dos Consórcios Intermunicipais de Saúde no estado do Paraná. Cadernos Metrópole, v. 18, n. 36, p. 377-399, 2016.

SEGATTO, C. I.; ABRUCIO, F. L. A cooperação em uma federação heterogênea: o regime de colaboração na educação em seis estados brasileiros. Revista Brasileira de Educaçáo, v. 21, n. 65, p. 411-429, 2016.

SILVA, C. R. et al. Dificuldade de acesso a serviços de média complexidade em municípios de pequeno porte: um estudo de caso. Ciência \& Saúde Coletiva, v. 22, n. 4, p. 1109-1120, 2017.

SIMÃO, N. M.; DALMO, F. C.; NEBRA, S. A. A Política Nacional de Resíduos Sólidos e a estratégia de formação dos Consórcios Públicos Intermunicipais. Revista de Políticas Públicas, v. 21, n. 2, p. 24, 2018.

STRELEC, T. C.; FONSECA, F. Desafios da adaptação institucional: um estudo do impacto da Lei de Consórcios Públicos no estado de São Paulo. Cadernos Adenauer, 2011. Disponível em: <https://bit.ly/3oyxd6k>. Acesso em: 10 set. 2018. 


\section{BIBLIOGRAFIA COMPLEMENTAR}

BRASIL. Ministério da Saúde. Portaria MS/GM nº 373, de 27 de fevereiro de 2002. Regionalização da Assistência à Saúde: aprofundando a descentralização com equidade no acesso: Norma Operacional da Assistência à Saúde: Noas-SUS 01/02. Diário Oficial da Uniáo, Brasília, 27 fev. 2002.

. Ministério da Saúde. Portaria n⿳0 1.473, de 24 de junho de 2011. Institui os comitês gestores, grupos executivos, grupos transversais e os comitês de mobilização social e de especialistas dos compromissos prioritários de governo organizados por meio de redes temáticas de atenção à saúde. Diário Oficial da União, Brasília, 24 jun. 2011.

Data da submissão: 11/6/2018

Primeira decisão editorial em: 23/10/2018

Última versão recebida em: 16/11/2018

Aprovação final em: 19/11/2018 